\title{
The Role of Culture in Health Reporting Bias
}

\author{
Xiaoxuan Yang \\ Harris School of Public Policy, University of Chicago, Chicago, USA \\ Email: xyang5@uchicago.edu
}

How to cite this paper: Yang, X. X. (2021). The Role of Culture in Health Reporting Bias. Open Journal of Social Sciences, 9, 7286.

https://doi.org/10.4236/jss.2021.94008

Received: March 11, 2021

Accepted: April 11, 2021

Published: April 14, 2021

Copyright $\odot 2021$ by author(s) and Scientific Research Publishing Inc. This work is licensed under the Creative Commons Attribution International License (CC BY 4.0).

http://creativecommons.org/licenses/by/4.0/

\begin{abstract}
In this paper, I creatively use the cognitive bias of self-control to express the differences between Eastern and Western cultures, and then clarify the formation mechanism of two types of health reporting behaviors: truthful reporting (in Western countries) and reporting only the good news while concealing unpleasant information (in East Asian countries). Using panel data from 13 countries from 2000 to 2016, I analyzed the role of culture in health reporting bias by using sex index and Confucianism dummy variable as proxy variables for culture. The results show that traditional variables have only a $50 \%$ explanatory ability in interpreting the reporting bias in health between East and West. Unobservable national individual factors such as culture that do not change over time can account for the remaining $44 \%$ of health reporting bias. Among these individual factors, $92.3 \%$ can be attributed to culture as represented by the sex index, and about $0.23 \%$ can be explained by the Confucianism dummy variable. In addition, the popularization of tertiary education can effectively correct the cognitive bias of self-control, thus eliminating the deep inhibition of culture on health reporting behavior. My research provides inspiration and technical support for improving the accuracy of self-reporting health in the future.
\end{abstract}

\section{Keywords}

The Role of Culture, Health Reporting Bias, Overweight Population, Self-Control, Cognitive Bias

\section{Introduction}

Previous scholars from various countries have studied health reporting bias from a variety of perspectives, mainly focusing on education, income level, age, gender, and social security. More specifically, higher education can reduce health reporting bias (Choi \& Cawley, 2018). Secondly, people with low income levels will have increased their health reporting bias (Etilé \& Milcent, 2006; Johnston et al., 
2009). Thirdly, older people are more inclined to self-report good health (Van Doorslaer \& Gerdtham, 2003; Lindeboom \& Van Doorslaer, 2004). Fourthly, women are more likely to report good health (Song \& Yoon, 1995; Lindeboom \& Van Doorslaer, 2004). Fifthly, social security can reduce people's health reporting bias (Mazeikaite et al., 2018). In addition, other factors affecting health reporting bias include social desirability bias (e.g., Choi \& Cawley, 2018) and cognitive issues such as having incorrect memory or failing to understand the survey questions (e.g., Brener et al., 2003).

In the above literature, higher education reduced the health reporting bias of US residents, but it did not explain the health reporting bias of British and Swedish residents. Johnston, Propper, \& Shields (2009) based on a UK health survey, found no statistically significant differences in false reporting rates for different levels of education. Van Doorslaer and Gerdtham (2003) found that the predictive effect of an individual's self-assessed health on subsequent survival did not vary depending on income and education. Moreover, income levels can explain the health reporting bias of both French and British residents, but it did not explain the health reporting bias of Swedish residents (Van Doorslaer \& Gerdtham, 2003). Additionally, unlike the role of the Canadian female population sample in health reporting bias (Lindeboom \& Van Doorslaer, 2004), the Swedish data suggests that Swedish men report more accurately (Van Doorslaer \& Gerdtham, 2003). Wada's (2005) analysis of Japanese women found no difference between reported and measured values. Therefore, a more comprehensive understanding of health reporting bias may require additional analysis of other factors. Because many of the decisions and choices people make in which they lack previous experience will be based not only on their current state but also on their previous beliefs (Guiso et al., 2006). A simple and intuitive guess is that cultural differences between the East and the West lead to national differences in health reporting bias. However, due to a bottleneck in the quantification of culture, the literature on this research direction is still very limited. Studies on health reporting bias are also restricted to individual countries or individual regions, such as Europe (Jürges, 2007). As a result, the mechanism of the effect of culture on health reporting bias is still in a black box, lacking normative theoretical analysis and empirical support.

The cultures of the East and West mainly affect the self-control of residents (Pirouz, 2009) and thus affect their health reporting behavior. The theoretical logic of this paper is that under the influence of culture, people will form a cognitive bias with different degrees of self-control. Cognitive bias of self-control makes the residents in different countries deviate from the real situation when reporting health status, so that they will report truthfully or overstate the positive. The basic theoretical expectation of this paper is that the greater the impact of Confucian culture on residents, the stronger their self-control and the more serious the cognitive bias. This influences them to report only the good while concealing what is unpleasant and vice versa. 
Using panel data of 13 countries from 2000 to 2016, I empirically test the above theoretical expectation. This paper regards self-control as a substitute variable of culture and expresses it with two groups of proxy variables: the first is sex index, the other is the dummy variable of the Confucian cultural circle (Hruschka \& Hadley, 2008). I found that the explanatory power of education, income level, age, gender and social security mentioned in the previous literature to explain the national differences of health reporting bias was only about $50 \%$. The other $44 \%$ of health reporting bias must be explained by other individual factors such as customs, religious beliefs, and cultural differences that do not change over time. About $92.3 \%$ of these individual factors can be attributed to the culture as represented by sex index, and $0.23 \%$ can be explained by the dummy variable of Confucian culture. These results suggest that culture is an important cause of health reporting bias.

The main contributions of this paper can be summarized in the following ways. First on the theoretical level, the two kinds of opposite Eastern and Western cultures are uniformly expressed by a self-control cognitive bias. Second, on the empirical level I use sex index and Confucian cultural circle dummy variable to measure culture. Based on cross-country panel data I examined the relationship between culture and health reporting bias, highlighting the superiority of using culture in explaining the national differences of health reporting bias over using the traditional variables such as education and income. Third, in terms of policy intervention the analysis of this paper provides a micro-foundation and technological innovation for countries to adjust the deviation of health reporting in the future.

The remaining structure of the paper is arranged as follows. Section 2 sorts out the relationship between Eastern and Western culture and cognitive bias. Section 3 introduces the source of data, the selection of core variables and the establishment of empirical models. Section 4 is an empirical analysis of the relationship between culture and health reporting bias. Section 5 provides policy discussions while my conclusions are included in Section 6.

\section{Typical Characteristics of Eastern and Western Culture}

The ideological and cultural development of Western countries has been mainly influenced by the humanistic spirit of ancient Greece whose essential characteristic was to pursue the independence and liberation of personality. During the period of modern European cultural renaissance, the independent humanistic thought of ancient Greece was further developed. This emphasized individual liberation and rational spirit, the pursuit of knowledge and truth and creating the future with rationality. Individualistic values occupy a dominant position in Western countries. However, East Asian countries are influenced by Confucian thought which emphasizes the rationality of social order to safeguard the overall interests of mankind. Confucius pointed out in The Analects of Confucius. $T s z e-L \hat{u}$ (Legge, 1971) that "The father conceals the misconduct of the son, and 
the son conceals the misconduct of the father. Uprightness is to be found in this." Confucius believed that the reason why the son refused to testify against his father's "stealing of sheep" was that he could not bear to see his father being punished. Testifying against his father's misconduct was against his family's best interest. Therefore, concealing this misconduct is a cultural norm of family relations which is in line with an "upright" character. Confucius emphasized the importance of maintaining family. That "fathers and sons should conceal each other" was introduced into the law by later generations. Later it developed into the principle of "concealing for the respected, for the sages and for the relatives", and has been further developed into the principle of "do not wash your dirty linen in public".

The Confucian cultural circle centered in China and included other parts of Asia. It formed from the process of Confucian dissemination. Confucian thought and culture have exerted far-reaching influence in these countries. The longterm influence of Confucianism makes people in East Asian countries feel at ease when reporting happy events while they tend to feel guilty when reporting sad news, thus forming an attitude of reporting only the good news instead of the bad. However, with the increasing proportion of people receiving higher education the people in East Asian countries have begun to have access to Western culture. People in Western countries have also started to understand Confucian culture of East Asia and people's rationality is affected accordingly (Sourdin, 2008). The cultural collision and integration of the world can indirectly start by influencing people's self-control (Pongratz, 2006), and then correct the inhibitions of culture on residents' health reporting behavior.

The above analysis leads to the following two hypotheses. Hypothesis 1: Health reporting bias is positively correlated with self-control. That is to say, the stronger the self-control, the easier it is to overreport one's health status, which leads to greater bias in health reporting. Hypothesis 2: The popularity of higher education helps to reduce the abnormal degree of reporting bias. Namely, the popularization of higher education will make the deviation of health reporting in different countries tend to the world average level.

\section{Empirical Strategy}

\subsection{Measurement of Core Variables}

Economists agree that culture affects economic behavior, outcomes and institutions (e.g., Guiso et al., 2006; Alesina \& Giuliano, 2015; Eugster \& Parchet, 2019). However, I find few empirical studies on this topic in the economic literature, possibly because measuring culture is difficult (Greif, 1994; Guiso et al., 2006). In recent years, interdisciplinary communication, better econometric techniques and expanded data have made it possible to measure culture. McGuire et al. (2012) examined the impact of religion on financial reporting. To measure religiosity, they used the answers to questions raised in the polls conducted by Gallup to construct religiosity scores. Moreover, based on the method of McGuire et 
al. (2012), Chourou's (2020) study added a dummy variable to measure the degree of religiosity in the county. Chen et al. (2016) studied the relationship between religious beliefs and the local governments' financing, investment and cash holding decisions. In their study, the degree of religious belief was defined as the number of religious adherents in a county to the total population in the county. Using the same logic, using religiosity as a proxy for culture, Jiang et al. (2018) used the proportion of people with religious beliefs in the area where the corporate headquarters is located to measure the corporate culture, thus examining the relationship between religious beliefs and the cost of debt. Additionally, Ang (2019) used Hofstede's (1980) measure of individualism to explore the relationship between the existing differences in the level of financial development and the degree of individual cultural orientation in different countries.

When choosing the measure of Eastern and Western culture (self-control), the analysis logic of this paper is that under the influence of culture, residents in Eastern and Western countries will form cognitive bias of self-control in different directions and degrees. This will lead to different health reporting bias. Therefore, a reasonable proxy variable of Eastern and Western cultures should not only represent the self-control of people in different countries, but also have obvious cultural characteristics. Thus, this paper uses sex index and Confucianism dummy variable as proxy variables of self-control. More specifically, 1) The sex indices include two indicators: the proportion of unprotected sex to total sex (Sex_unsafe) and the age of first sex (Sex_age). The first index is negatively correlated with self-control, and the second index is positively correlated with self-control. The choice of sex indices as proxy variables for self-control is mainly due to the close association between sexual behavior and self-control which has received a lot of support in the psychology and sex science literature. For example, people with low self-control tend not to take safety measures during sex (Trobst et al., 2002; Quinn \& Fromme, 2010) and have a relatively low age of first sex (Toates, 2009). More importantly, Gailliot and Baumeister (2007) found that people who exhibit strong self-control in other behaviors (such as financial management, consumption, fulfilling tasks on time, etc.) also have better control over their sexual behavior. 2) Confucianism dummy variable is used to proxy culture. As mentioned above, Western culture emphasizes the expression of self-worth while Confucian culture makes people restrain themselves and report only good news instead of unloading one's problems. Therefore the Confucianism dummy variable can qualitatively (though roughly) measure two types of cognitive biases of self-control: the countries of the Confucian cultural circle (some East Asian countries) are characterized by excessive self-control, while the countries that are not in the Confucian cultural circle (European and American countries) show insufficient self-control.

Health reporting bias is defined as the deviation between actual health measurements and self-reported health values. This paper uses data from the overweight and obese populations of the OECD (Organization for Economic Co- 
operation and Development) official website to measure health reporting bias. This data is very suitable for this research because it is presented based on both self-report data (height and weight estimates from population-based health interview surveys) and measured data (accurate estimates of height and weight from health examinations) and is measured by the percentage of people aged 15 and over. More importantly, this indicator contains panel data from 1978-2017 in a total of 37 countries (i.e., OECD 36 member countries and Indonesia), which is very suitable for comparative research across countries.

\subsection{Empirical Models}

To test Hypothesis 1, I estimate the following linear regression model:

$$
\operatorname{Diff}_{i t}=\beta_{0}+\beta_{1} X_{i t}+\beta_{2} \text { Controls }_{i t}+\varepsilon_{i t},
$$

where the subscript $i$ represents the country, the subscript $t$ indexes the year and $\varepsilon$ is a random error term. Diff is the reporting bias of the proportion of overweight population, which is defined as the difference between the actual measured proportion of overweight population in each country and the proportion of self-reported overweight population. Diff of negative value is adjusted to 0 , which is regarded as truthful reporting. $X$ is a vector of the proxy variables of culture (self-control), which includes sex indices (Sex_unsafe, Sex_age) and the Confucianism dummy variable. Controls is a set of control variables mentioned in the previous literature and above that can affect health reporting bias, including per capita income (Lngdpper), social security (Socialspend), female population ratio (Sex_ratio), elderly population ratio (Olderpop) and popularization of higher education $(E d u)$.

To test Hypothesis 2, I estimate the following linear regression model:

$$
\mid \text { Ex_Diff }_{i t} \mid=\alpha+\gamma_{1} \text { Edu }_{i t}+\gamma_{2} \mid \text { Ex_Sex }_{i t} \mid+u_{i t} \text {, }
$$

in which $\mid$ Ex_Diff $\mid$ is the degree of deviation between the actual health reporting bias and the world average health reporting bias (the absolute value indicates that only the degree of deviation is measured without distinguishing the direction of the deviation). Edu indicates the popularity of higher education. |Ex_Sex| represents cognitive bias of self-control, measured by the difference between the sex index of the $t$ th country in the year $t$ and the sample mean in that year (the absolute indicates that only the degree of deviation is measured without distinguishing the direction of the deviation). If Hypothesis 2 is reasonable, we expect that the coefficient of Edu $\gamma_{1}$ should be significantly negative after controlling the degree of self-control cognitive bias (|Ex_Sex $\mid$ ).

\subsection{Data Sources and Summary Statistics}

The data in this paper mainly come from the OECD official website statistics. To measure health reporting bias, my sample is limited to countries that have completed self-reporting and actual measurements. Finally, I got panel data covering 13 countries (Australia, Canada, Chile, Czech Republic, Estonia, France, Hungary, 
Table 1. Summary statistics and data sources.

\begin{tabular}{cccccc}
\hline Variable & Mean & Sd & Min & Max & Definition and data source \\
\hline Diff & 0.071 & 0.026 & 0.000 & 0.120 & Reporting bias of overweight population $^{\mathrm{a}, \mathrm{e}}$ \\
Sex_ratio & 0.506 & 0.009 & 0.499 & 0.533 & Female population ratio $^{\mathrm{b}}$ \\
Olderpop & 0.132 & 0.022 & 0.088 & 0.184 & 65+ population ratio $^{\mathrm{a}, \mathrm{b}}$ \\
Lngdpper & 10.394 & 0.540 & 9.234 & 11.689 & Logarithmic per capita GDP $^{\mathrm{b}}$ \\
Edu & 0.377 & 0.097 & 0.145 & 0.530 & $\begin{array}{c}\text { \% people receiving higher education } \\
\text { a }\end{array}$ \\
Socialspend & 0.155 & 0.052 & 0.076 & 0.283 & Social security expenditure/GDP $^{\mathrm{a}}$ \\
Confucianism & 0.250 & 0.441 & 0.000 & 1.000 & 1 for Confucian cultural circle, 0 for others $^{\mathrm{c}}$ \\
Sex_unsafe & 0.515 & 0.044 & 0.414 & 0.618 & \% people having unprotected sex $^{\mathrm{d}}$ \\
Sex_age & 16.994 & 0.143 & 16.800 & 17.300 & Age of first sex $^{\mathrm{d}}$ \\
\hline
\end{tabular}

Notes: 1) The number of samples for Sex_unsafe and Sex_age is 17, and the number of samples for other variables is 28. 2) The data sources are abbreviated as follows. a: OECD official website data; b: World Bank database; c: Organized by this paper: the Confucian cultural circle includes China, Hong Kong, Indonesia, Japan, Korea, Malaysia, Philippines, Singapore, Thailand and Vietnam; d: Durex's global survey; e: Pengpid \& Peltzer, 2017.

Indonesia, Ireland, Korea, Latvia, Luxembourg and United States) for 16 years from 2000 to 2016. Data on the sex index comes from Durex's global survey. Table 1 shows the calculation methods, basic statistics and data sources of the main variables in the paper.

\section{Empirical Results and Analysis}

\subsection{The Test Results of Hypothesis 1}

To test Hypothesis 1, I estimated the model (1) using OLS and the regression results are presented in Table 2. In column (1), I focus on the effects of variables mentioned in previous literature on health reporting bias. Among them, the coefficient of female proportion (Sex_ratio) is significantly negative, indicating that the larger the proportion of female population, the smaller the bias of health reporting, which implies that women are more inclined to report truthfully than men. The coefficient of elderly population ratio (Olderpop) is significantly negative, implying that the older the population is, the smaller the deviation in health reporting. Namely, older people tend to report more accurately than younger people. The coefficient of income level (Lngdpper) is significantly negative, demonstrating that the health report bias of high-income people is small. That is, high-income people tend to report more truthfully than low-income people. The coefficients of higher education coverage (Edu) and social security (Socialspend) are significantly positive, suggesting that the population receiving higher education and the population of countries with higher social security level tended to overreport their health. I note that the model's $A d j-R^{2}$ is only 0.512 , which means that in the sample of this paper the explanatory variables emphasized in the previous literature have limited interpretation ability. As mentioned earlier, unobservable individual factors such as culture largely influence people's health 
Table 2. Test results of Hypothesis 1: the effect of self-control on health reporting bias.

\begin{tabular}{|c|c|c|c|c|c|c|}
\hline & (1) & (2) & (3) & (4) & (5) & (6) \\
\hline \multirow[t]{2}{*}{ Sex_ratio } & $-2.368^{\star *}$ & $-6.608^{\star}$ & -105.502 & $-15.505^{\star * *}$ & -2.798 & -1.619 \\
\hline & $(-2.71)$ & $(-1.80)$ & $(-1.26)$ & $(-9.60)$ & $(-1.21)$ & $(-1.42)$ \\
\hline \multirow[t]{2}{*}{ Olderpop } & $-0.826^{\star \star}$ & 0.505 & 78.033 & $-0.439^{\star}$ & $-1.010^{\star}$ & $-1.060^{* *}$ \\
\hline & $(-2.24)$ & $(0.86)$ & $(1.85)$ & $(-2.04)$ & $(-2.10)$ & $(-2.43)$ \\
\hline \multirow[t]{2}{*}{ Lngdpper } & $-0.057^{\star \star \star}$ & 0.007 & -1.964 & 0.010 & $-0.045^{\star *}$ & $-0.050^{* * *}$ \\
\hline & $(-3.86)$ & $(0.24)$ & $(-1.91)$ & $(0.94)$ & $(-2.25)$ & $(-3.06)$ \\
\hline \multirow[t]{2}{*}{$E d u$} & $0.219^{* * *}$ & -0.402 & 0.795 & $-0.267^{\star * *}$ & $0.270^{\star * *}$ & $0.217^{\star * *}$ \\
\hline & $(3.11)$ & $(-1.53)$ & $(0.50)$ & $(-4.12)$ & $(3.41)$ & $(3.08)$ \\
\hline \multirow[t]{2}{*}{ Socialspend } & $0.807^{* * *}$ & -0.208 & 5.708 & -0.244 & $0.751^{* *}$ & $0.908^{\star * *}$ \\
\hline & $(4.79)$ & $(-1.32)$ & $(1.89)$ & $(-1.43)$ & $(2.92)$ & $(4.64)$ \\
\hline \multirow[t]{2}{*}{ Sex_unsafe } & & & & $-1.150^{* * *}$ & & \\
\hline & & & & $(-8.59)$ & & \\
\hline \multirow[t]{2}{*}{ Sex_age } & & & & & $0.089^{*}$ & \\
\hline & & & & & $(2.15)$ & \\
\hline \multirow[t]{2}{*}{ Confucianism } & & & & & & 0.018 \\
\hline & & & & & & $(1.01)$ \\
\hline \multirow[t]{2}{*}{ Constant } & $1.763^{* * *}$ & $3.391^{*}$ & 64.418 & $8.593^{* * *}$ & 0.346 & $1.323^{*}$ \\
\hline & $(3.64)$ & (1.79) & $(1.41)$ & (10.13) & $(0.22)$ & $(2.03)$ \\
\hline Individual effect & No & Yes & Yes & No & No & No \\
\hline Annual effect & No & No & Yes & No & No & No \\
\hline $\operatorname{Adj-} R^{2}$ & 0.512 & 0.953 & 0.915 & 0.919 & 0.536 & 0.513 \\
\hline
\end{tabular}

Notes: 1$\left.)^{*} p<0.1,{ }^{* *} p<0.05,{ }^{* *} p<0.01 .2\right)$ The t statistics calculated by Huber-White's robust standard error method are in parentheses. 3) Dependent variables are all the reporting bias of overweight population (Diff).

reporting behavior. To this end, in column (2), I further added 13 dummy variables that reflect the individual effects of the country. At this time, the Adj- $\mathrm{R}^{2}$ of the model increased to 0.953 , which means that individual factors (such as customs, culture, etc.) that do not change over time can further explain about $44.1 \%(=0.953-0.512)$ health reporting bias. In column (3), I further added the annual dummy variables reflecting the time characteristics and found that in most years the corresponding dummy variables are not significant. This shows that the health reporting behavior of residents in different countries has a high degree of stability in the sample interval of this paper.

From the above analysis, we can see that the control variables emphasized in the previous literature do not seem to be able to fully explain the differences in health reporting bias between different countries. Although the results in column (2) show that individual effects can largely explain cross-sectional differences in health reporting bias, I am more curious about what is in the black box 
of individual effects.

To this end, in the columns (4)-(6), I respectively added the proxy variables reflecting the Eastern and Western cultures based on the model setting in column (1). It should be noted that in the regression analysis of columns (4)-(6), I did not include national dummy variables reflecting individual effects for two reasons. First, the focus of my analysis is to reveal the specific composition of individual effects. Second, since the sex index and the Confucian cultural circle dummy variable do not change over time, they will be completely collinear with the individual effect dummy variables. If I include them at the same time, the validity of statistical inference will be greatly reduced.

In columns (4) and (5), I used the proportion of unprotected sex (Sex_unsafe) and the age of first sex (Sex_age) as alternative indicators for Eastern and Western cultures (self-control), respectively. From the results in column (4), the estimated coefficient of Sex_unsafe is -1.150 , which is significantly different from zero at the $1 \%$ level. This means that the higher the proportion of people having unprotected sex (the weaker their self-control ability), the more likely they are to report their health accurately, which is in line with our expectations above. From the overall goodness of fit of the model, Adj- $\mathrm{R}^{2}$ in column (4) is increased by $40.7 \%(=0.919-0.512)$ than column (1), indicating that $92.3 \%(=40.7 \% / 44.1 \%)$ of the individual effects mentioned above can be explained by Eastern and Western cultures. As a robustness test, in column (5), I used another proxy variable that more intuitively reflects self-control the age of first sex (Sex_age). Its coefficient estimate is significantly positive at the $10 \%$ level, indicating that the stronger the self-control, the easier it is to increase the health reporting bias. At this time, the goodness of fit Adj- $\mathrm{R}^{2}$ of the model is 0.536, which is about 2.4\% higher than that of column (1) $(=0.536-0.512)$. This implies that about $5.4 \%$ $(=2.4 \% / 44.1 \%)$ of the individual effects can be attributed to the Eastern and Western cultures as represented by self-control.

In column (6), I added the Confucian cultural circle dummy variable, whose estimation coefficient is positive but not significant. In addition, in the sample of this paper the average value of the overweight population reporting bias (Diff) is 0.071 (see Table 1), which indicates that the reporting bias of the Confucian cultural circle is about $25.35 \%(=0.018 / 0.071)$ higher than the sample average, ceteris paribus. From the overall goodness of fit of the model, Adj- $\mathrm{R}^{2}$ in column (4) is increased by $0.1 \%(=0.513-0.512)$ than column (1), indicating that about $0.23 \%(=0.1 \% / 44.1 \%)$ of the individual effects mentioned above can be explained by Confucian culture. Confucianism dummy variable has less explanatory ability than I expected. I think the main reason is that the countries that belong to the Confucian cultural circle account for a relatively small proportion in my entire analysis sample (including only Korea and Indonesia while Japan is excluded because of too many missing values). At the same time, it also shows that sex index can well reflect the cultural differences between different countries. Therefore, I will use Sex_unsafe to measure self-control and the corresponding 
national culture in the follow-up analysis.

The above analysis shows that Hypothesis 1 of this paper, health reporting bias is positively correlated with self-control has received relatively robust empirical support. The scatter plots in Figure 1 and Figure 2 can more intuitively reflect the above conclusions.

The vertical axes in Figure 1 and Figure 2 are both the reporting bias (Diff) defined in model (1). The horizontal axes in Figure 1 and Figure 2 are variables reflecting national culture (self-control): the proportion of unprotected sex

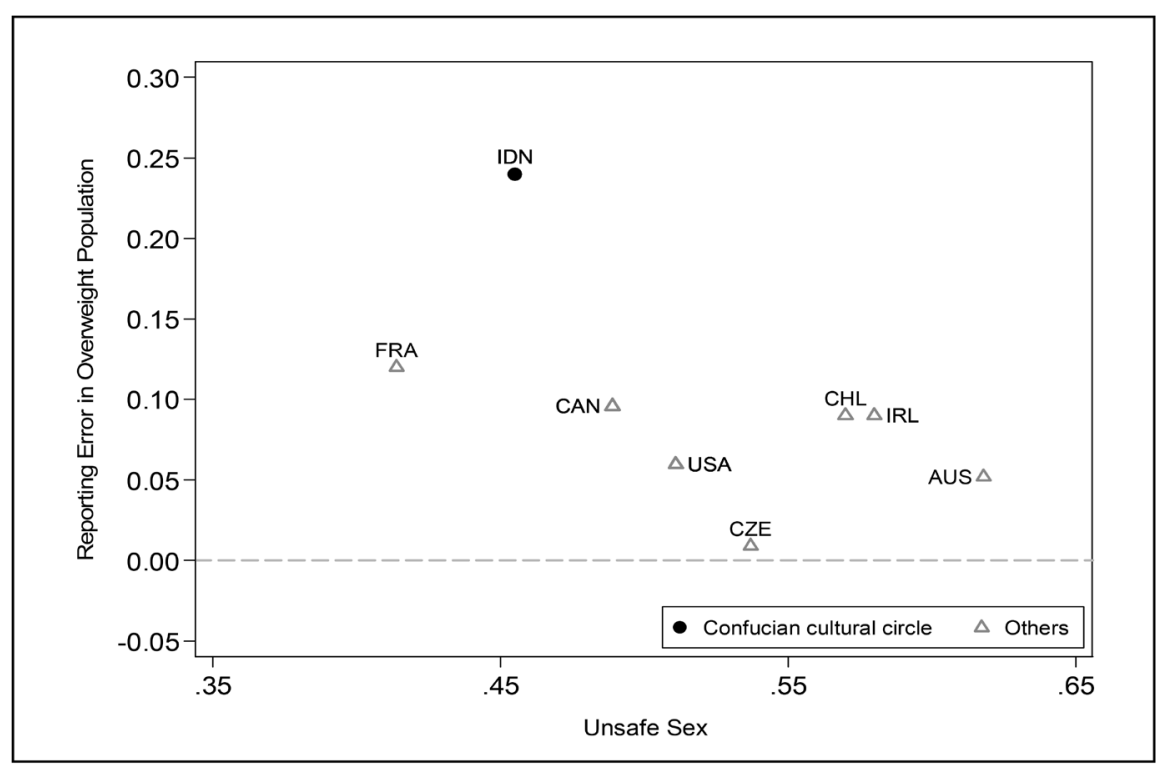

Note: The country names are abbreviated as AUS (Australia), FRA (France), IDN (Indonesia), CAN (Canada), CHL (Chile), IRL (Ireland), CZE (Czech Republic), and USA (United States). The same abbreviations will be used again in the following figure.

Figure 1. Reporting bias and unprotected sex ratio.

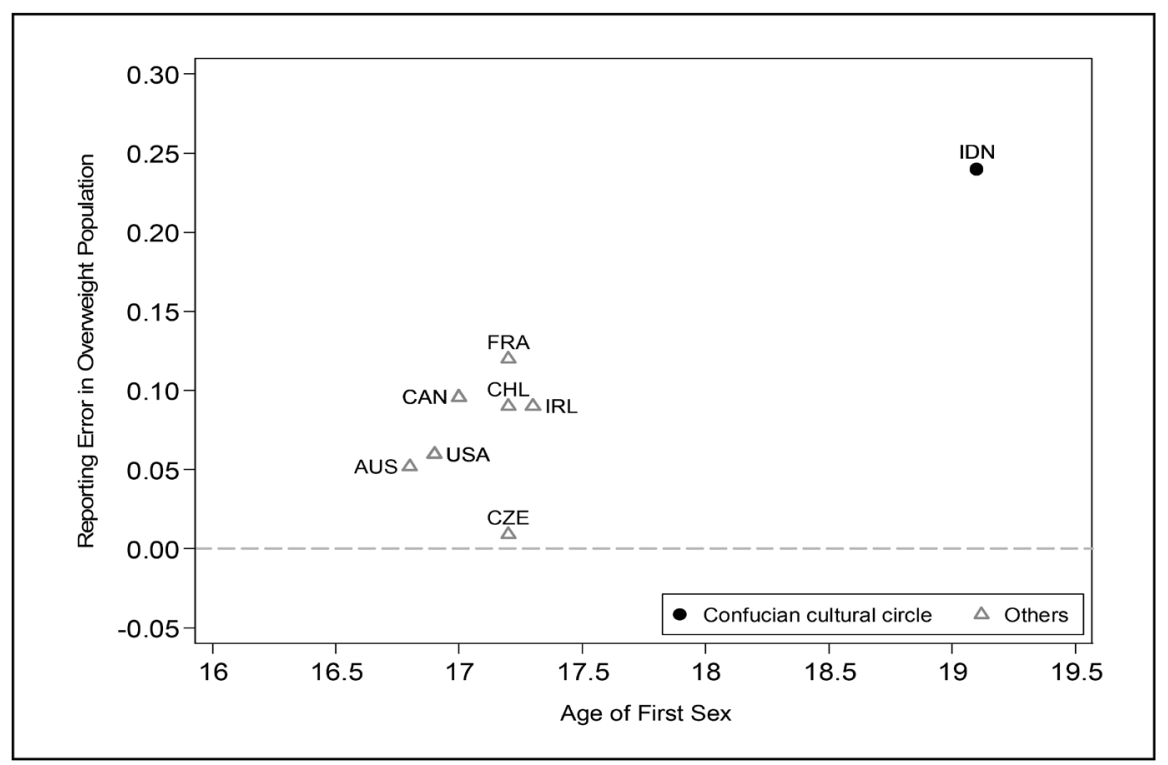

Figure 2. Reporting bias and age of first sex. 
(Sex_unsafe) and the age of first sex (Sex_age), respectively. Therefore, the slope of the scatter plot in Figure 1 and Figure 2 can be considered as the marginal impact of self-control (culture) on reporting bias. From another perspective, it also reflects the significant correlation between reporting bias and cultural variables. As can be seen from these figures, Indonesia, which belongs to the Confucian cultural circle, shows a clear high reporting bias (Korea is not shown in these figures due to missing data on sex indices). Most countries, however, that belong to the non-Confucian cultural circle are more inclined to report truthfully. Among them, the three most accurate countries are the Czech Republic (CZE), the United States (USA) and Australia (AUS).

\subsection{The Test Results of Hypothesis 2}

Table 3 presents the estimated results of model (2), and the dependent variables are the degree of dispersion of reporting bias (|Ex_Diff|). In panel A, I measured self-control cognitive bias using the degree of dispersion of unsafe sex ratios (|Ex_sex_unsafe|). We are interested in column (3), in which I added Edu and $\mid$ Ex_sex_unsafe| at the same time. The coefficient of $\mid$ Ex_sex_unsafe| is estimated to be -0.394 , which is significant at the $5 \%$ level, indicating that the greater the self-control cognitive bias, the more serious the reporting bias. In other words, it shows that the degree of national cultural differences corresponds to the degree of abnormality of reporting bias, which further verifies the rationality of Hypothesis 1.

The coefficient of Edu is significantly negative at the $1 \%$ level, which indicates

Table 3. Test results of Hypothesis 2: popularity of higher education and abnormal degree of reporting bias.

\begin{tabular}{cccc} 
& $(1)$ & $(2)$ & $(3)$ \\
\cline { 2 - 4 } Panel A: & & $\mid$ Ex_Diff $\mid$ & \\
\hline Ex_sex_unsafe $\mid$ & $-0.243(-1.21)$ & & $-0.394^{* *}(-2.61)$ \\
Edu & & & $-0.196^{* * *}(-4.20)$ \\
Constant & $0.038^{* *}(2.66)$ & $0.071^{* * *}(4.19)$ & $0.122^{* * *}(5.41)$ \\
$N$ & 21 & 35 & 21 \\
Adj- $R^{2}$ & 0.023 & 0.196 & 0.479 \\
Panel B: & & & $0.063^{* * *}(5.68)$ \\
$\mid$ Ex_sex_age $\mid$ & $0.074^{* * *}(6.18)$ & $-0.132^{* * *}(-3.05)$ & $-0.096^{* *}(-2.80)$ \\
Edu & & $0.071^{* * *}(4.19)$ & $0.040^{* *}(2.68)$ \\
Constant & $0.001(0.10)$ & 35 & 21 \\
$N$ & 21 & 0.196 & 0.742 \\
Adj-R & 0.650 & & \\
\hline
\end{tabular}

Notes: 1$\left.)^{*} p<0.1,{ }^{* *} p<0.05,{ }^{* *} p<0.01 .2\right)$ The $\mathrm{t}$ statistics calculated by Huber-White's robust standard error method are in parentheses. 
that after controlling the self-control cognitive bias, the increase in the popularity of higher education helps to reduce the abnormal degree of reporting bias. This result initially confirms Hypothesis 2 and indicates that Hypothesis 2 is a further deepening of Hypothesis 1.

As a robustness test, in Panel B, I used the degree of deviation of the age of first sex (|Ex_sex_age|) as a control variable of cultural differences in different countries. The results are consistent with those in Panel A, indicating that the empirical analysis of Hypothesis 2 in this paper is robust.

\section{Policy Implications}

According to the empirical results of this paper, the proportion of women, the proportion of the elderly and the income level are significantly negatively correlated with the bias of health reports. Therefore, the self-reporting health of women, the elderly and high-income groups is more credible. The degree of popularity of higher education and social security level are positively correlated with health reporting bias, which indicates that people who have received higher education and those in countries with high levels of social security are more likely to exaggerate self-reporting health.

The important finding of this paper is that culture is an important factor explaining the country differences in health reporting bias: the stronger the influence of Confucian culture, the greater the deviation of health reporting. Furthermore, culture mainly influences people's health reporting behavior by influencing their self-control. The stronger the self-control, the greater the health reporting bias. Therefore, it is possible to carry out a policy design to improve the deviation of health reporting of residents from a cultural perspective. Specifically, it can be started from two aspects. On the one hand, we can directly cut in from the cultural point of view and promote the concept of truthful health reporting. Because new social and ecological environments can create new cultural patterns through modifications of one's repeated or habitual behavior (Broesch \& Hadley, 2012). On the other hand, we can indirectly influence the deviation of residents' self-control by expanding the popularity of higher education, and then correct the excessive restraint of Confucian culture on residents' health reporting behavior.

\section{Conclusion}

On an ideological level, this paper uses the cognitive bias of self-control to describe the influence of Eastern and Western culture on residents' health reporting behavior. In this way I explain the differences in health reporting behavior between the East and the West. The main theoretical conclusion of this paper is that the deeper the influence of Confucian culture, the stronger the self-control and the higher the deviation of health reporting. Similarly, the deeper the influence of Western culture, the weaker the self-control and the lower the deviation of health reporting. 
On an empirical level, by controlling the traditional variables such as education, income level, age, gender and social security, this paper regards sex index and Confucianism dummy variable as proxy variables for Eastern and Western cultures to regress between culture and reporting bias in health with panel data of 13 countries from 2000 to 2016 . The results show that culture is indeed an important factor affecting the bias of health reporting. Traditional variables have only about a $50 \%$ explanative ability for national difference in health reporting bias. Individual factors that do not change over time can account for the remaining $44 \%$ of health reporting bias. Among these individual factors, about $0.23 \%$ can be explained by the Confucianism dummy variable and $92.3 \%$ can be attributed to the culture represented by the sex index. Secondly, the degree of dispersion of health reporting bias is significantly positively correlated with the degree of cognitive bias from self-control, indicating a one-to-one correspondence between cultural differences and differences of health reporting behavior. Thirdly, the degree of dispersion of health reporting bias is significantly negatively correlated with the popularity of higher education, indicating that the increase in higher education helps to reduce the degree of reporting bias.

At the level of policy operation, the empirical conclusions of this paper indicate that as the fundamental internal cause of health reporting bias, culture, mainly affects the health reporting behavior by influencing the self-control of residents. Therefore, it is possible to carry out a policy design that improves the bias of health reporting of residents in various countries from a cultural perspective.

\section{Acknowledgements}

The author thanks the editor and anonymous referees for their helpful comments. The author is most grateful to Prof. John Mullahy for his guidance and help. The author also thanks Dr. James Broesch for valuable advice on cultural measurement.

\section{Conflicts of Interest}

The author declares no conflicts of interest regarding the publication of this paper.

\section{References}

Alesina, A., \& Giuliano, P. (2015). Culture and Institutions. Journal of Economic Literature, 53, 898-944. https://doi.org/10.1257/jel.53.4.898

Ang, J. B. (2019). Culture, Legal Origins, and Financial Development. Economic Inquiry, 57, 1016-1037. https://doi.org/10.1111/ecin.12755

Brener, N. D., Billy, J. O., \& Grady, W. R. (2003). Assessment of Factors Affecting the Validity of Self-Reported Health-Risk Behavior among Adolescents: Evidence from the Scientific Literature. Journal of Adolescent Health, 33, 436-457. https://doi.org/10.1016/S1054-139X(03)00052-1

Broesch, J., \& Hadley, C. (2012). Putting Culture Back into Acculturation: Identifying and Overcoming Gaps in the Definition and Measurement of Acculturation. The Social 
Science Journal, 49, 375-385. https://doi.org/10.1016/j.soscij.2012.02.004

Chen, Y., Murgulov, Z., Rhee, S. G., \& Veeraraghavan, M. (2016). Religious Beliefs and Local Government Financing, Investment, and Cash Holding Decisions. Journal of Empirical Finance, 38, 258-271. https://doi.org/10.1016/j.jempfin.2016.07.009

Choi, A., \& Cawley, J. (2018). Health Disparities across Education: The Role of Differential Reporting Error. Health Economics, 27, e1-e29. https://doi.org/10.1002/hec.3609

Chourou, L. (2020). Does Religiosity Matter to Value Relevance? Evidence from US Banking Firms. Journal of Business Ethics, 162, 675-697.

https://doi.org/10.1007/s10551-018-3978-Z

Etilé, F., \& Milcent, C. (2006). Income-Related Reporting Heterogeneity in Self - Assessed Health: Evidence from France. Health Economics, 15, 965-981. https://doi.org/10.1002/hec.1164

Eugster, B., \& Parchet, R. (2019). Culture and Taxes. Journal of Political Economy, 127, 296-337. https://doi.org/10.1086/700760

Gailliot, M. T., \& Baumeister, R. F. (2007). Self-Regulation and Sexual Restraint: Dispositionally and Temporarily Poor Self-Regulatory Abilities Contribute to Failures at Restraining Sexual Behavior. Personality and Social Psychology Bulletin, 33, 173-186. https://doi.org/10.1177/0146167206293472

Greif, A. (1994). Cultural Beliefs and the Organization of Society: A Historical and Theoretical Reflection on Collectivist and Individualist Societies. Journal of Political Economy, 102, 912-950. https://doi.org/10.1086/261959

Guiso, L., Sapienza, P., \& Zingales, L. (2006). Does Culture Affect Economic Outcomes? Journal of Economic Perspectives, 20, 23-48. https://doi.org/10.1257/jep.20.2.23

Hofstede G. H. (1980). Culture's Consequences: International Differences in Work-Related Values (p. 294). Beverly Hills, CA: Sage Publications.

Hruschka, D. J., \& Hadley, C. (2008). A Glossary of Culture in Epidemiology. Journal of Epidemiology \& Community Health, 62, 947-951.

https://doi.org/10.1136/jech.2008.076729

Jiang, F., John, K., Li, C. W., \& Qian, Y. (2018). Earthly Reward to the Religious: Religiosity and the Costs of Public and Private Debt. Journal of Financial and Quantitative Analysis, 53, 2131-2160. https://doi.org/10.1017/S002210901800039X

Johnston, D. W., Propper, C., \& Shields, M. A. (2009). Comparing Subjective and Objective Measures of Health: Evidence from Hypertension for the Income/Health Gradient. Journal of Health Economics, 28, 540-552. https://doi.org/10.1016/j.jhealeco.2009.02.010

Jürges, H. (2007). True Health vs Response Styles: Exploring Cross-Country Differences in Self-Reported Health. Health Economics, 16, 163-178. https://doi.org/10.1002/hec.1134

Legge, J. (1971). Confucius: Confucian Analects, the Great Learning and the Doctrine of the Mean. New York: Dover.

Lindeboom, M., \& Van Doorslaer, E. (2004). Cut-Point Shift and Index Shift in Self-Reported Health. Journal of Health Economics, 23, 1083-1099. https://doi.org/10.1016/j.jhealeco.2004.01.002

Mazeikaite, G., O’Donoghue, C., \& Sologon, D. M. (2018). The Great Recession, Financial Strain and Self-Assessed Health in Ireland. The European Journal of Health Economics, 1-18. https://doi.org/10.2139/ssrn.3213417

McGuire, S. T., Omer, T. C., \& Sharp, N. Y. (2012). The Impact of Religion on Financial Reporting Irregularities. The Accounting Review, 87, 645-673. 
https://doi.org/10.2308/accr-10206

Pengpid, S., \& Peltzer, K. (2017). The Prevalence of Underweight, Overweight/Obesity and Their Related Lifestyle Factors in Indonesia, 2014-2015. Aims Public Health, 4, 633-649. https://doi.org/10.3934/publichealth.2017.6.633

Pirouz, D. (2009). Culture, Self-Control, and Consumer Financial Behavior. ACR North American Advances.

Pongratz, L. A. (2006). Voluntary Self-Control: Education Reform as a Governmental Strategy. Educational Philosophy and Theory, 38, 471-482. https://doi.org/10.1111/j.1469-5812.2006.00205.x

Quinn, P. D., \& Fromme, K. (2010). Self-Regulation as a Protective Factor against Risky Drinking and Sexual Behavior. Psychology of Addictive Behaviors, 24, 376-385. https://doi.org/10.1037/a0018547

Song, Y. M., \& Yoon, J. L. (1995). The Accuracy of Self-Reported Weight and Height. Korean Journal of Epidemiology, 17, 257-268.

Sourdin, P. (2008). Pension Contributions as a Commitment Device: Evidence of Sophistication among Time-Inconsistent Households. Journal of Economic Psychology, 29, 577-596. https://doi.org/10.1016/j.joep.2007.12.005

Toates, F. (2009). An Integrative Theoretical Framework for Understanding Sexual Motivation, Arousal, and Behavior. Journal of Sex Research, 46, 168-193.

https://doi.org/10.1080/00224490902747768

Trobst, K. K., Herbst, J. H., Masters III, H. L., \& Costa Jr., P. T. (2002). Personality Pathways to Unsafe Sex: Personality, Condom Use, and HIV Risk Behaviors. Journal of Research in Personality, 36, 117-133. https://doi.org/10.1006/jrpe.2001.2334

Van Doorslaer, E., \& Gerdtham, U.-G. (2003). Does Inequality in Self-Assessed Health Predict Inequality in Survival by Income? Evidence from Swedish Data. Social Science \& Medicine, 57, 1621-1629. https://doi.org/10.1016/S0277-9536(02)00559-2

Wada, K., Tamakoshi, K., Tsunekawa, T., Otsuka, R., Zhang, H., Murata, C. et al. (2005). Validity of Self-Reported Height and Weight in a Japanese Workplace Population. International Journal of Obesity, 29, 1093-1099. https://doi.org/10.1038/sj.ijo.0803012 